\title{
Determination of Plasma Protein Binding by Microdialysis Coupled with Online Capillary Electrophoresis Electrochemiluminescence
}

\author{
XIANG Qian, YANG Xiaodong ${ }^{a^{*}}$, GAO Ying ${ }^{b^{*}}$ \\ Changchun Institute of Technology, Changchun 130021, China \\ aemail: y86908051@126.com, bemail:gaoy5680@163.com
}

\begin{abstract}
Keywords: Ultrasonic microdialysis; Electrochemiluminescence; Capillary electrophoresis; Plasma protein binding; Chlorpheniramine maleate

Abstract. An ultrasonic microdialysis coupled with online capillary electrophoresis electrochemiluminescence method has been established for the sensitive determination of plasma protein binding. The drug and blood plasma were mixed in different molar ratios and incubated at $37{ }^{\circ} \mathrm{C}$ in $10 \mathrm{mmol} / \mathrm{L}$ phosphate buffer $(\mathrm{pH} \mathrm{7.5)}$ in a water bath. The concentration of unbound chlorpheniramine maleate was determined by CE-ECL. The conditions affecting separation and detection were investigated. Under the optimized conditions: ECL detection at 1.2V, dialysis time $1.5 \mathrm{~h}$, protein binding rate of chlorpheniramine maleate with human plasma protein were determinated. The human plasma protein binding rate of chlorpheniramine maleate was $72.3 \%$.
\end{abstract}

\section{Introduction}

In general, Only the unbound drug is active and capable of diffusing across membrane, whereas bound drug hardly passes through the blood capillary walls to reach the action site. Furthermore, the presence of direct or indirect competition between two drugs or between a drug and an endogenous compound (e.g., a fatty acid) for the same binding proteins can be an important source of drug-drug interactions or drug displacement effects. So, plasma protein binding is an important factor in establishing pharmacokinitic and pharmacodynamic properties of a drug, which it determin the activity, distribution, rate of excretion, and toxicity of drugs in the body [1].

Chlorpheniramine maleate, as an antihistamine, has been widely used for symptomatic relief of common colds and allergic diseases. Among the analytical techniques, high-performance liquid chromatography (HPLC) [2,3] have been used for the determination of chlorpheniramine maleate. Capillary electrophoresis-Ru(bpy) ${ }_{3}{ }^{2+}$ lectrochemiluminescence is a highly sensitive and selective detection means in analytical chemistry because of its excellent stability and high efficiency in the aqueous phase. Also, it has found many applications such as in immunoassays and for detection of a number of biologically important species without derivatization [4-6].

In this work, a fast and sensitive technique was developed to determine the binding of chlorpheniramine maleate with plasma protein using CE-ECL detection after ultrasonic microdialysis.

\section{Experimental}

Chemicals and materials. Chlorpheniramine maleate standard samples were purchased from National Institute for the Control of Pharamaceutical and Biological Products, Ministry of Health (Beijing, China). All reagents used in the analysis were of analytical purity and used without further purification. Tris(2,2'-bipyridyl) ruthenium ( II ) chloride hexahydrate was obtained from Aldrich Chemical Co.(Milwaukee, WI, USA).

Sample preparation. Blood plasma samples from patients who were undergoing chemotherapy were provided by The First Affiliated Hospital to Changchun University of Chinese Medicine. plasma samples were kept frozen until used. In the experiment, plasma samples were prepared by mixing the plasma samples after they were defrosted in a $37^{\circ} \mathrm{C}$ water bath.

Instrumentation and electrophoretic conditions. The separation and detection of analytes 
employed a integrative CE-ECL system (Xi'an Remax Electronics Co. Ltd, Xi'an, China). Electrokinetic injected at $10 \mathrm{kV}$ for $10 \mathrm{~s}$. By using a constant voltage of $15 \mathrm{kV}$ applied with the anode at the injection end, the elecrophoretic separation was performed in a $50 \mathrm{~cm}$ uncoated fused-silica capillary with $50 \mu \mathrm{m}$ i.d. and $360 \mu \mathrm{m}$ o.d., which obtained from Yongnian Optical Fabric Factory (Hebei, China). The separation capillary was treated with $0.1 \mathrm{M} \mathrm{NaOH}$ overnight, and then flushed for $10 \mathrm{~min}$ with water and $10 \mathrm{~min}$ with the running buffer prior to use. A solution consisting of $5 \mathrm{mM}$ $\mathrm{Ru}(\mathrm{bpy})_{3}{ }^{2+}$ and $50 \mathrm{mM}$ phosphate at $\mathrm{pH} 7.5$ as background electrolyte was added to ECL detection cell. Column-end detection of ECL were employed using three-electrode system consisting of $\mathrm{Ag} / \mathrm{AgCl}$ as the reference electrode and Pt wire as the counter electrode and Pt disk as the working electrode. A voltage of $800 \mathrm{~V}$ was supplied at PMT installed below the ECL detection cell. The ECL signal was measured with PMT and processed with a data processor controlled by a computer.

Procedure for microdialysis. Microdialysis is a selective sampling technique in the sense that no large molecules enter surrounding buffer. The dialysis membrane has molecular weight cutoff ranging from 8000 to 14000 . It allows free drug crossing the dialysis membrane and diffusing into the surrounding buffer due to the concentration gradient of free drug from the outside to the inside of the microdialysis membrane. The overall chlorpheniramine maleate concentration remains apparently constant during the experiment.

\section{protein binding studies.}

Equilibrium dialysis were investigated in order to study the time needed to reach a stable dialysate concentration. Chlorpheniramine maleate were mixed with different volumes of blood plasma. Dialysis tubes with different volume ratios were incubated at $37{ }^{\circ} \mathrm{C}$ in phosphate buffer in a water bath. The concentration of unbound chlorpheniramine maleate was determined by CE-ECL.

The relative recovery $R$ was estimated according to the following equation

$$
R=\frac{C_{\text {dialysate }}}{C_{m}}
$$

where $C_{\mathrm{m}}$ was the total drug concentration, and $C_{\text {dialysate }}$ the drug concentration in microdialysate.

Free drug concentration $(\mathrm{Cu})$ in the surrounding medium was determined by dividing the concentration $C_{\text {dialysate }}$ by the recovery $(R)$ according to the following equation

$$
C_{\mathrm{u}}=\frac{C_{\text {dialysate }}}{R}
$$

Protein binding rate $(B \%)$ was calculated as follows

$$
B \%=\frac{\left(C_{\mathrm{m}}-C_{\mathrm{u}}\right)}{C_{\mathrm{m}}} \times 100 \%
$$

\section{Results and discussion}

Effect of detection voltage. ECL intensity of analyte in CE-ECL system is significantly affected by the detection voltage, which provides a crucial ECL coreaction platform for the analyte and ruthenium species. So, the hydrodynamic voltammograms for chlorpheniramine maleate standard solution were investigated for assessing the effect of the working potential on the ECL responses in a potential range of $1.00 \sim 1.40 \mathrm{~V}$ (Fig.1). When the detection potential was $1.00 \mathrm{~V}$, no evident ECL signals appeared in electropherogram. However, at potentials higher than $1.00 \mathrm{~V}$, the ECL intensities of four alkaloids began to increase sharply. ECL intensity of narcotine exhibited maximum ECL response at $1.15 \mathrm{~V}$, sequentially. When the potential went above $1.20 \mathrm{~V}$, ECL responses no longer increased, An optimum detection potential was achieved at $1.20 \mathrm{~V}$ after evaluating the sensitivity, the background current, and base line noise, offering the most favorable signal-to-noise characteristics.

Choice of equilibrium dialysis time. Equilibrium dialysis were investigated in order to study the time needed to reach a stable dialysate concentration. $100 \mu 1$ of chlorpheniramine maleate $\left(1.25 \times 10^{-2}\right.$ mol/L) were mixed with $140 \mu 1,240 \mu 1$ of blood plasma, separately. Samples with different volume ratios between drug and blood plasma were incubated at $37^{\circ} \mathrm{C}$ in $10 \mathrm{mmol} / \mathrm{L}$ phosphate buffer $(\mathrm{pH}$ 
7.5) in a water bath. The concentration of unbound chlorpheniramine maleate was determined by CE-ECL at $30 \mathrm{~min}$ intervals. As can be seen from Fig. 2, the signal intensity of unbound chlorpheniramine maleate exhibited dependence on the dialysis time. An increase in the equilibrium dialysis time from $0.5-4.5 \mathrm{~h}$ resulted in an enhancement in the ECL intensity. When exceeded 1.5h, stable ECL intensitiy of the analyte was observed, an optimum dialysis time was obtained at $1.5 \mathrm{~h}$.

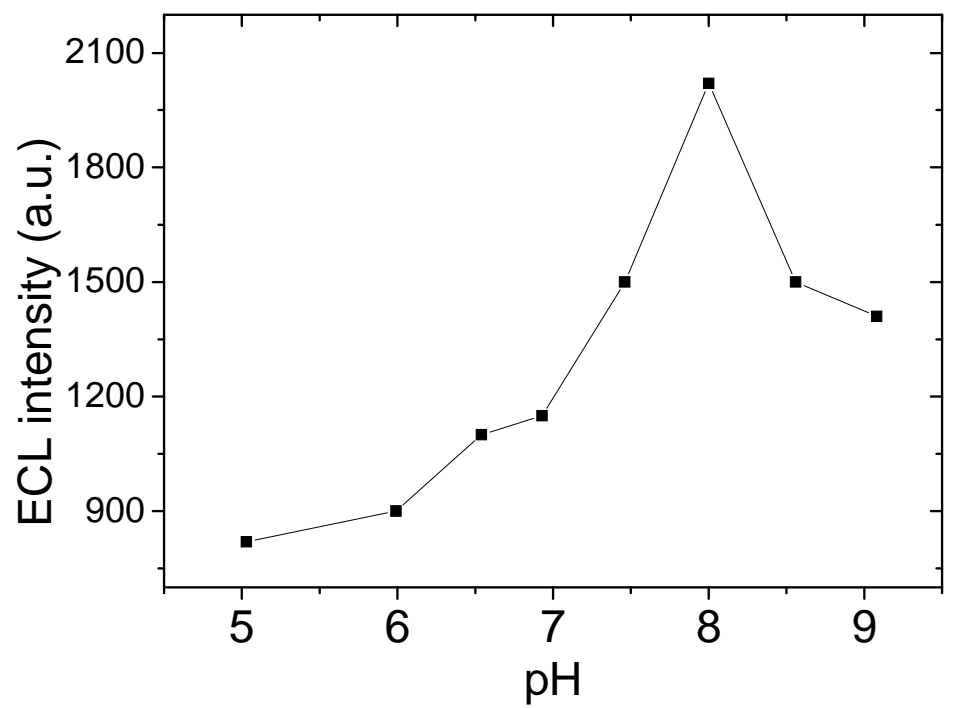

Figure.1. Effect of detection potential on the ECL intensity of chlorpheniramine maleate. $5 \mathrm{mmol} / \mathrm{L}$ $\mathrm{Ru}(\mathrm{bpy})_{3}{ }^{2+}$ and $50 \mathrm{mmol} / \mathrm{L}$ phosphate buffer in the detection reservoir; electrokinetic injection, $10 \mathrm{~s}$ at $10 \mathrm{kV}$; separation voltage, $15 \mathrm{kV}$.

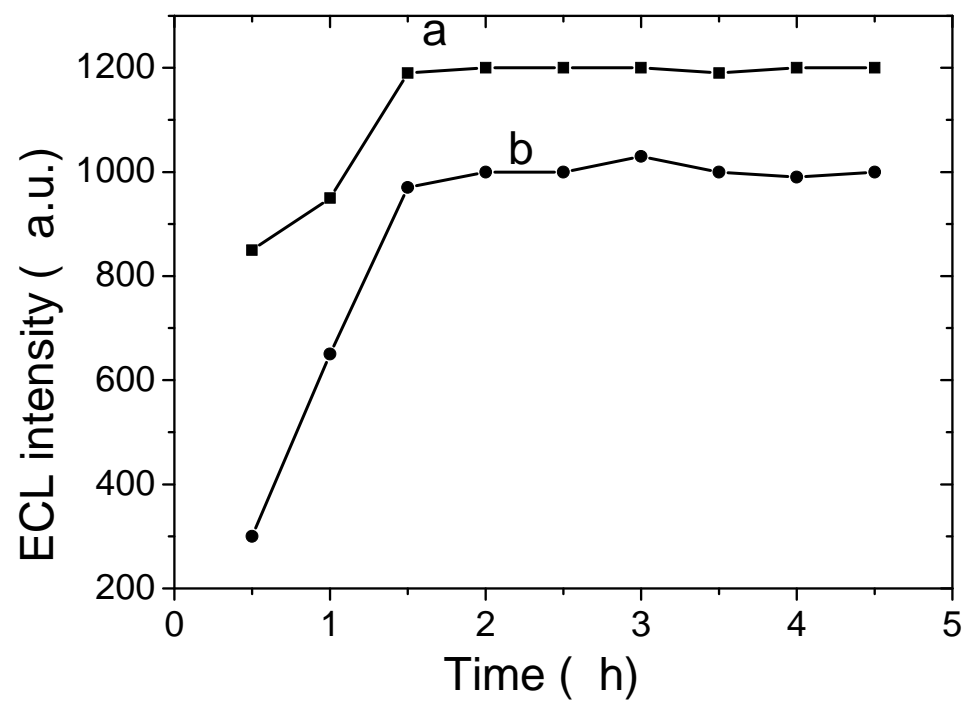

Figure.2. Relationship between ECL intensity and dialysis time. Incubation temperature, $37^{\circ} \mathrm{C}$; solution inside dialysis bag, $100 \mu 1$ of chlorpheniramine maleate and $140 \mu \mathrm{l}$ (b), $240 \mu 1$ (a) of blood plasma; solution outside dialysis bag, $10 \mathrm{mmol} / \mathrm{L}$ phosphate buffer ( $\mathrm{pH} 7.5)$; other conditions were the same as Fig.1.

Protein binding rate of chlorpheniramine maleate with human plasma protein. Under the optimized conditions: ECL detection at $1.2 \mathrm{~V}$, dialysis time $1.5 \mathrm{~h}$, protein binding rate of chlorpheniramine maleate with human plasma protein were determinated. Table 1 listed the protein binding rate data in chlorpheniramine maleate with human plasma protein mixed solution with 
different concentration sampled by microdialysis for $1.5 \mathrm{~h}$ and analyzed by CE-ECL. The human plasma protein binding rate of chlorpheniramine maleate was $72.3 \%$. The bound parameters reported here were consistent with those published in literature. This agreement indicates the reliability of the present method.

Table 1 Protein binding rate of chlorpheniramine maleate with human plasma protein

\begin{tabular}{llllll}
\hline $\begin{array}{l}\text { No. } \\
\text { Total concentration } \\
(\mathrm{mol} / \mathrm{L})\end{array}$ & $\begin{array}{l}\text { Bound drug } \\
\text { concentration } \\
(\mathrm{mol} / \mathrm{L})\end{array}$ & $\begin{array}{l}\text { Unbound } \\
\text { concentration } \\
(\mathrm{mol} / \mathrm{L})\end{array}$ & $\begin{array}{l}\text { Protein binding } \\
\text { rate }(\%)\end{array}$ & \\
\hline 1 & $8.9 \times 10^{-5}$ & $6.2 \times 10^{-5}$ & $2.7 \times 10^{-5}$ & 69.7 & 72.3 \\
2 & $1.8 \times 10^{-4}$ & $1.2 \times 10^{-4}$ & $6.0 \times 10^{-5}$ & 66.7 & \\
3 & $3.6 \times 10^{-4}$ & $2.8 \times 10^{-4}$ & $8.0 \times 10^{-5}$ & 77.8 & \\
4 & $5.4 \times 10^{-4}$ & $4.0 \times 10^{-4}$ & $1.4 \times 10^{-4}$ & 74.1 & \\
5 & $8.9 \times 10^{-4}$ & $6.5 \times 10^{-4}$ & $2.4 \times 10^{-4}$ & 73.0 & \\
\hline
\end{tabular}

\section{Summary}

The microdialysis coupled with online capillary electrophoresis electrochemiluminescence method was employed to analyze plasma protein binding. The drug and blood plasma were mixed in different molar ratios and incubated at $37^{\circ} \mathrm{C}$ in $10 \mathrm{mmol} / \mathrm{L}$ phosphate buffer $(\mathrm{pH} 7.5)$ by microdialysis for $1.5 \mathrm{~h}$. The concentration of unbound chlorpheniramine maleate was determined by CE-ECL. The human plasma protein binding rate of chlorpheniramine maleate was $72.3 \%$. It is concluded that the microdialysis coupled with CE-ECL method is a powerful technique for study of the human plasma protein binding rate has become an alternative, competitive and supplementary method for HPLC, because of its special attributes.

\section{Acknowledgements}

This project was supported by National Natural Science Foundation of China (No. 51275055 and No. 21427811), the Scientific and Technological Developing Scheme of Jilin Province (No.201205042,), and the Natural Science Foundation of Jilin Province, China (No. 20140101153JC), and the Foundation of Department of Education of Jilin Province (No. 2015287)

\section{References}

[1] David S. Hage, Abby Jackson, Matthew R. Sobansky, John E. Schiel, Michelle J. Yoo, K. S. Joseph: J. Sep. Sci. Vol. 32 (2009), p. 835

[2] M. Yamaguchi, H. Monji, K. Yamashita, I. Aoki, T. Yashiki: J. Chromatogr. B Vol. 661 (1994), p.168

[3] C. Celma, J. A. Allué, J. Pruñonosa, C. Peraire, R. Obach: J.Chromatogr. A Vol. 870 (2000), p.77

[4] K.A. Fähnrich, M. Pravda, G.G. Guilbault: Talanta Vol. 54 (2001), p.531

[5] Y. Du, E.Wang: J. Sep. Sci. Vol. 30 (2007), p.875

[6] B.A. Gorman, P.S. Francis, N.W. Barnett: Analyst Vol. 131 (2006), p.616 